\title{
Spatial Statistical Analysis on Geographical agglomeration of planting Industry in Sichuan Province
}

\author{
Shouying Ying, Qiaoxi Fan ${ }^{1}$ \\ ${ }^{1}$ School of Statistics, Chengdu University of Information Engineering, Chengdu, 610103
}

Keywords: Sichuan Province; Planting Industry; Geographical Agglomeration; Spatial Autocorrelation Analysis

\begin{abstract}
Based on the data of planting area from 2000 to 2016 in Sichuan Province, spatial dependence and heterogeneity of planting industry in Sichuan Province were investigated by using spatial Gini coefficient method, global spatial autocorrelation analysis and local spatial autocorrelation analysis. Furthermore, the distribution pattern and spational temporal evolution of geographical agglomeration characteristics of planting industry are further studied. It is found that there is no obvious geographical agglomeration in grain crops, but the economic crops have strong characteristics of geographic agglomeration and typical positive spatial autocorrelation. There are significant characteristics of high - high cluster, low-low cluster and high-low cluster in local areas. The spatial distribution pattern of Sichuan province shows a spatial distribution pattern of "west low East High", and the cluster state of crops is distinct.
\end{abstract}

\section{Introduction}

Since the 1930s, the spatial distribution of agriculture began to appear obvious phenomenon of geographical agglomeration. Under the influence of market changes and national policies, China's dominant agricultural products are increasingly concentrated in the dominant regions. and the geographical agglomeration of planting industry is obviously characterized by "small increase at first, then significant increase, and then tend to weaken." ${ }^{[1]}$ With the faster development of agricultural scale and specialization, regionalization development, Aciksoz(2009) ${ }^{[2]}$ and Mutlu M $\mathrm{N}(2014)^{[3]}$ regard that the urban agricultural agglomeration pattern in Turkey has been basically formed and has shown a trend of development. Chatterjee $\mathrm{T}$ et al. (2016) ${ }^{[4]}$ using agricultural income, it was found that non-geographical factors are the key factors driving agglomeration of agriculture in India. To study agricultural production structure, we must pay attention to the spatial distribution of agriculture. At present, the research on agriculture geographical agglomeration in China mainly focuses on the development trend, function and measurement of agricultural industrial agglomeration level. ${ }^{[6-10]}$ The existing literature has the following characteristics: the research object is mainly food crops, less literature both on food and economic crops; the research area is mostly national, the provincial level research is relatively less. The production mode of decentralized management of traditional peasant households has gradually changed to the specialization of agriculture and the regionalization of production mode. Sichuan Province is the only major grain producing area in the western region. The structure and layout of agricultural production have an important impact on the agricultural production in the western region. Based on this, this paper will take Sichuan as the research object.

\section{Data sources and research methods}

\subsection{Data sources and processing}

Because the yield level of planting industry is easily affected by natural disasters, this paper will select the planting area as research object. In order to ensure the consistency of the data, the planting area data are derived from Sichuan Statistical Yearbook, Sichuan Rural Yearbook and Chinese Statistical Yearbook. Considering the small changes of the agricultural planting area in a 
short time, this paper selects the data from five years of 2000,2005,2010,2015,2016 to analyze. Based on the existing literature research and available data, this paper mainly focuses on rice, beans, potato, cotton, oil and sugar in the planting industry.

\subsection{Research methods}

According to the first law of geography, in the spatial statistical analysis, Spatial Gini Coefficient and Spatial Autocorrelation Coefficient (Moran's I index) is widely used to test the existence of spatial dependence and spatial heterogeneity.

\subsubsection{Spatial gini coefficient}

Spatial Gini coefficient is widely applied to study industrial geographic agglomeration. By measuring the degree of industrial agglomeration, it reflects the uneven distribution of industrial geography. The formula is as follows:

$$
G=\sum_{i=1}^{n}\left(\frac{x_{i j}}{X_{j}}-\frac{y_{i}}{Y}\right)^{2}
$$

Among them, $n$ is the area number, $x_{i j}$ is the planting area of the $\mathrm{j}$ crop in the $\mathrm{i}$ area; $\mathrm{x}_{\mathrm{i}}$ is the planting area of the $\mathrm{j}$ crops in the high level area; $\mathrm{y}_{\mathrm{i}}$ is the total planting area of the crops in the $\mathrm{i}$ area; $Y$ is that the total planting area in the high level area. The value of $G$ is $[0,1]$. If the value is closer to 0 , the more balanced the geographical distribution of the $\mathrm{j}$ crops in the $\mathrm{i}$ area; If the value is closer to 1 , the stronger the geographical concentration of the industry.

\subsubsection{Global spatial autocorrelation analysis}

Global Moran's I index is an overall survey of the spatial autocorrelation of planting industry, and reveals the agglomeration characteristics of the spatial layout of planting industry. The calculation formula is as follows:

$$
\text { Moran's } I_{i}=\frac{\sum_{k=1}^{m} \sum_{h=1}^{m} W_{k h}\left(x_{k}^{i}-\bar{x}\right)\left(x_{h}^{i}-\bar{x}\right)}{\frac{1}{m} \sum_{k=1}^{m}\left(x_{k}^{i}-\bar{x}\right) \times\left(\sum_{k=1}^{m} \sum_{h=1}^{m} W_{k h}\right)}, \quad \bar{x}=\frac{1}{m} \sum_{k=1}^{m} x_{k}^{i}
$$

Among them, $\mathrm{m}$ is the number of regions and $\mathrm{i}$ is the type of crop. $x_{k}^{i}\left(x_{h}^{i}\right)$ indicates that the planting area of $\mathrm{i}$ crops in $\mathrm{k}(\mathrm{h})$ area accounts for the proportion of $\mathrm{j}$ crop planting area in the whole country. $W_{\mathrm{kh}}$ represents the first order adjacent spatial weight matrix of binary, which element settings are followed by the usual method of document processing. If the $\mathrm{k}$ area is adjacent to the $\mathrm{h}$ area, the value of $W_{\mathrm{kh}}$ is 1 , otherwise the value is 0 .The interval of Moran 's I index is [-1,1]. When the value is 0 , it means that the planting industry presents a random spatial distribution; When the value is closer to 1 , the spatial distribution has a positive spatial autocorrelation; When the value is closer to -1 , the spatial distribution has negative spatial autocorrelation.

\subsubsection{Local spatial autocorrelation analysis}

Due to the Global Spatial Autocorrelation Analysis ignores the potential instability of spatial process, it can not reflect the characteristics of local planting agglomeration. Therefore, Local Moran's I index is used to analyze the possible local autocorrelation, examined whether there is a high value agglomeration or low value agglomeration in the $\mathrm{k}$ area and adjacent areas. The formula is as follows:

$$
\text { Local Moran's } I_{k}=\frac{\left(x_{k}-\bar{x}\right)}{\sum_{k=1}^{m}\left(x_{k}-\bar{x}\right)^{2}} \times \sum_{h \neq k}^{m} W_{k h}\left(x_{h}-\bar{x}\right)
$$

Among them, $\mathrm{m}$ is the area number, $\mathrm{x}_{\mathrm{k}}\left(\mathrm{x}_{\mathrm{h}}\right)$ represents the planting area of planting area in $\mathrm{K}$ $(\mathrm{H})$ area. $\mathrm{W}_{\mathrm{kh}}$ is identified ibid. If it is positive, there may be "high high cluster" or "low low cluster" 
in this area; if it is negative, there may be "low high cluster" or "high low cluster" in this area. What kind of situation is it, we need to use Moran's I scatter diagram and LISA cluster diagram to decide.

\section{Spatial Statistical Analysis of Geographical agglomeration of Sichuan planting industry}

\subsection{The degree of geographical agglomeration of sichuan planting industry}

\subsubsection{Estimation of geographical concentration degree based on spatial Gini coefficient}

The average spatial Gini coefficient of grain crops is 0.0003 , which indicates that there is no obvious geographical accumulation in Sichuan Province.The average value of spatial Gini coefficient of economic crops is 0.0035 higher than that of grain crops, indicating that the geographical distribution of economic crops in Sichuan Province is relatively concentrated compared with grain crops, in which the geographical concentration of cotton is high, the mean spatial Gini coefficient is 0.3723 , followed by sugar and oil crops.

According to the development trend, although the spatial Gini coefficient of planting industry in Sichuan is decreasing, some crops gather obviously. It is worth noting that the geographical agglomeration degree of legume crops is relatively low, and the spatial Gini coefficient of legume crops shows the trend of "decrease first then rise then decrease"; The geographical concentration of potato crops and cotton showed a significant growth trend. The Gini coefficient of other crops showed a decreasing trend, which widespread planting in Sichuan has not yet formed obvious gather. Therefore, on the whole, the geographical concentration of economic crops is higher than that of grain crops and the geographical agglomeration situation of cotton, potato and legume crops is obvious.

Table 1 Spatial Gini coefficient of planting in Sichuan Province

\begin{tabular}{c|c|c|c|c|c|c|c|c}
\hline \multirow{2}{*}{ year } & \multirow{2}{*}{$\begin{array}{c}\text { Grain } \\
\text { Crops }\end{array}$} & Rice & Beans & Tubers & \multirow{2}{*}{$\begin{array}{c}\text { Economic } \\
\text { Crops }\end{array}$} & Cotton & $\begin{array}{c}\text { Oil-bearing } \\
\text { crops }\end{array}$ & $\begin{array}{c}\text { Sugar } \\
\text { Crops }\end{array}$ \\
\hline 2000 & 0.0004 & 0.0052 & 0.0082 & 0.0031 & 0.0051 & 0.1173 & 0.0090 & 0.0590 \\
\hline 2005 & 0.0005 & 0.0049 & 0.0072 & 0.0031 & 0.0053 & 0.1858 & 0.0097 & 0.0522 \\
\hline 2010 & 0.0002 & 0.0063 & 0.0056 & 0.0023 & 0.0036 & 0.3907 & 0.0076 & 0.0429 \\
\hline 2015 & 0.0004 & 0.0045 & 0.0128 & 0.0076 & 0.0019 & 0.5622 & 0.0067 & 0.0296 \\
\hline 2016 & 0.0003 & 0.0039 & 0.0083 & 0.0077 & 0.0016 & 0.6057 & 0.0066 & 0.0313 \\
\hline $\begin{array}{l}\text { mean } \\
\text { value }\end{array}$ & 0.0003 & 0.0050 & 0.0084 & 0.0048 & 0.0035 & 0.3723 & 0.0079 & 0.0430 \\
\hline
\end{tabular}

Note: grain crops in the table are not limited to rice, beans and potatoes; economic crops are same.

\subsubsection{Estimation of geographic concentration degree based on global spatial autocorrelation analysis}

From the point of view of grain crops and economic crops, it can be seen from Table 2 that the global Morans I index of grain crops in 2000-20016 has not passed the significance test under the global spatial autocorrelation analysis, which indicates that there is no obvious spatial similarity distribution of grain crops. That is, there is no significant geographical agglomeration phenomenon, and this conclusion is the same as the above conclusion. This has something to do with the grain security policy of Sichuan Province, which has achieved a "balance of total amount and basic self-sufficiency" for a long time. As a big grain producing province, the prefectures ensure grain supply, and the proportion of grain sown area is always stable at more than $80 \%$. Secondly, as a traditional agricultural area, rice, beans, potato and other food crops are still widely cultivated, thus, grain crops in Sichuan showed a random distribution trend.

The global Moran's I index of the economic crops passed the significant test at $1 \%$ and $5 \%$ levels in 200-2010 years, and it is positive. This shows that Sichuan's economic crops have obvious agglomeration characteristics at this stage, and shows a typical positive spatial autocorrelation. However, in 2015 and 2016, the global Moranos I index of economic crops did not pass the significance test, which indicated that the economic crops were randomly distributed at this stage. 
The geographical concentration of economic crops is decreasing gradually, which is in line with the above conclusions. With the development of agricultural modernization, Some of the economic crops with high added value can break through the geographical limitation by modern agricultural production technology and grow in various regions and expand the planting scope.

It is worth noting that the spatial autocorrelation of cotton has obvious stages. From 2000 to 2005, due to resource endowment and agricultural production technology constraints, cotton crops in Sichuan showed significant positive correlation. With the readjustment of regional agricultural production structure, the regional superiority industry and characteristic industry has given priority to development, compared with Xinjiang province, there is no advantage over cotton planting in Sichuan. As a result, cotton growing areas in Sichuan are decreasing and the planting areas are dispersing. In addition, the oilseed and sugar crops in Sichuan are affected by the spatial adjacent area and have significant positive spatial autocorrelation characteristics, showing the geographical accumulation phenomenon between similar values, that is, the oil and sugar crops are high value regions adjacent to high value regions and low value regions adjacent to low value regions. As the same time, the spatial autocorrelation of oil has a downward trend;The spatial autocorrelation of sugar crops has the characteristics of stages, showing a trend of "decrease first and then rise", which is related to the fluctuation of market environment and the adjustment of agricultural structure, the geographical concentration of sugar crops was obvious.

Table 2 Morans I index of Sichuan planting industry

\begin{tabular}{|c|c|c|c|c|c|c|c|c|}
\hline \multirow[b]{2}{*}{ year } & \multirow{2}{*}{$\begin{array}{l}\text { Grain } \\
\text { Crops }\end{array}$} & \multirow[b]{2}{*}{ Rice } & \multirow[b]{2}{*}{ Beans } & \multirow[b]{2}{*}{ Tubers } & \multirow{2}{*}{$\begin{array}{l}\text { Economic } \\
\text { Crops }\end{array}$} & \multirow[b]{2}{*}{ Cotton } & \multirow[b]{2}{*}{$\begin{array}{c}\text { Oil-bearing } \\
\text { crops }\end{array}$} & \multirow[b]{2}{*}{$\begin{array}{l}\text { Sugar } \\
\text { Crops } \\
\end{array}$} \\
\hline & & & & & & & & \\
\hline 2000 & 0.0146 & 0.0659 & -0.0427 & 0.0065 & $0.3314^{* * *}$ & $0.8712^{* * *}$ & $0.4359^{* * *}$ & $0.4855^{* * *}$ \\
\hline 2005 & 0.0259 & 0.1156 & -0.0601 & 0.1088 & $0.3407^{* * *}$ & $0.6326^{* *}$ & $0.4771^{* * *}$ & $0.1909^{* *}$ \\
\hline 2010 & 0.0092 & 0.1165 & -0.0447 & 0.0903 & $0.2486^{* *}$ & 0.0526 & $0.4066^{* * *}$ & $0.1952^{* *}$ \\
\hline 2015 & 0.0416 & 0.1639 & 0.0700 & -0.0850 & 0.1213 & 0.0052 & $0.4047^{* * *}$ & $0.4488^{* * *}$ \\
\hline 2016 & -0.0128 & 0.1273 & 0.0888 & -0.0953 & 0.0629 & $-0.0237^{*}$ & $0.3553^{* * *}$ & $0.4427^{* * *}$ \\
\hline
\end{tabular}

Note: grain crops in the table are not limited to rice, beans and potatoes; economic crops are same.

\subsection{Distribution pattern and temporal spatial evolution of geographical agglomeration in sichuan province}

\subsubsection{Distribution pattern of geographical agglomeration of planting industry in Sichuan Province}

The spatial correlation of planting industry in Sichuan province is analyzed above, but the spatial correlation of different crops in different regions can not be judged and the spatial distribution characteristics of planting industry can not be observed. Therefore, in order to further analyze the relevance of planting industry in local space.

According to the significance of global autocorrelation in 2016, crops are divided into two categories (Table 3). The following characteristics are found: first, there are differences in spatial accumulation patterns among different crops. Taking potato as an example, there are three patterns of spatial agglomeration, which are characterized by high -high cluster in the area of Dazhou, which is surrounded by a large area of potato cultivation. In Panzhihua, a low-high cluster was formed, while in Liangshan area, a high-low cluster was formed. Secondly, the significant geographical agglomeration is mainly concentrated in the low level of economic development. In Ganzi, Aba, Liangshan, Dazhou, Guangan and other places, the spatial agglomeration appeared, mainly in the pattern of high-high agglomeration and low-low agglomeration. it is mainly due to the climatic conditions and geographical environment constraints, crop production has a strong regional, typical crops for example rice, oil, sugar and other crops. Thirdly, there is no consistency between global spatial autocorrelation and local spatial autocorrelation. In the global autocorrelation analysis, there were significant local autocorrelation analysis. This indicates that the global autocorrelation analysis results are likely to mask the local correlation. The global analysis is not significant, the 
local significance may exist.

Table 3 Local spatial agglomeration patterns of six crops in Sichuan in 2016

\begin{tabular}{|c|c|c|c|c|c|}
\hline & Crop species & $\begin{array}{l}\text { quadrant } 1 \\
\text { (high-high } \\
\text { cluster), }\end{array}$ & $\begin{array}{c}\text { quadrant } 2 \\
\text { (low-high } \\
\text { cluster) }\end{array}$ & $\begin{array}{c}\text { quadrant } 3 \\
\text { (low-low } \\
\text { cluster) }\end{array}$ & $\begin{array}{c}\text { quadrant } 4 \\
\text { (high-low } \\
\text { cluster) }\end{array}$ \\
\hline \multirow{3}{*}{$\begin{array}{c}\text { Unsignificant } \\
\text { Global spatial } \\
\text { autocorrelation }\end{array}$} & Rice & - & - & Ganzi & - \\
\hline & Beans & Guangan & - & Aba & - \\
\hline & Tubers & Dazhou & Panzhihua & - & Liangshan \\
\hline \multirow{3}{*}{$\begin{array}{c}\text { Significant } \\
\text { Global spatial } \\
\text { autocorrelation }\end{array}$} & Cotton & - & - & - & Suining \\
\hline & $\begin{array}{c}\text { Oil-bearing } \\
\text { crops }\end{array}$ & $\begin{array}{c}\text { Nanchong,Dazh } \\
\text { ou }\end{array}$ & - & Ganzi & - \\
\hline & Sugar Crops & Yibi,Luzhou & - & Aba & - \\
\hline
\end{tabular}

Note: all four types of agglomeration in table have passed the significance test at the $5 \%$ level.

\subsubsection{Temporal and Spatial Evolution of Geographical agglomeration of planting Industry in Sichuan Province}

As shown in Figure 1, the LISA cluster map of the four years shows that the planting industry in Sichuan province has a significant geographical agglomeration in the local spatial autocorrelation analysis, and shows a obvious trend of geographical agglomeration and the spatial pattern evolution of "west low East High".

(1) Based on regional spatial heterogeneity, planting industry in Sichuan Province has significant spatial disequilibrium distribution characteristics. As a big agricultural city in Sichuan, Nanchong and Dazhou are rich in agricultural resources, infrastructure and convenient transportation conditions. Organic agriculture are developing rapidly. The two cities are connected in geographical space. The planting industry has a high proportion of total sown area and is surrounded by areas with the proportion of the total planting area of high agricultural crops, thus forming a geographical agglomeration area adjacent to the high value and high value areas. The planting industry has a significant spatial spillover effect. As the provincial capital center, under the adjustment of industrial structure, the planting industry in Chengdu shows a remarkable spatial distribution characteristic of high-low cluster, and the high value region is surrounded by low value area. Due to the fragile ecological environment and the scarcity of resources, the backward agricultural infrastructure and the poor transportation conditions, the planting industry of Ganzi prefecture mainly depends on the preferential policies of the government. The planting industry in Ganzi has formed a distinct spatial distribution characteristic of low-low cluster.

(2) Based on the trend of agglomeration, the planting industry in Sichuan Province has obvious spatial distribution pattern of "west low-east high". As shown in Figure 1, compared with 2000 and 2005, the geographical agglomeration of Sichuan planting industry showed a significant local expansion in the LISA cluster map of the total crop sown area of Sichuan Province in 2010 and 2016. The geographical agglomeration types of planting industry are increasing gradually, and the core area of high-high cluster is increasing. The reason is that with the development of agricultural modernization in Sichuan, the consumption demand has become the focus of the adjustment of the agricultural industry structure and the overall layout of the region , Nanchong and Dazhou have been continuously consolidated as commodity grain bases and agricultural production bases and become state-level agricultural demonstration zones. The enhancement of social agglomeration promotes the agglomeration of agricultural development in some parts of Sichuan.
(a) 2000
(b) 2005
(c) 2010
(d) 2016

Fig. 1 Lisa agglomeration of total planting area of crops in Sichuan 


\section{Conclusion and Revelation}

This paper makes an empirical analysis of the spatial distribution and evolution trend of the geographical agglomeration of Sichuan planting industry by using the method of spatial statistical analysis. The main conclusions are as follows:

(1) Based on the analysis of spatial Gini coefficient, the geographical concentration of economic crops in Sichuan is higher than that of grain crops, and cotton, potato and legume crops have obvious geographical agglomeration. High-added-value crop scale, specialization, regionalization planting situation is bright.

(2) Based on the global spatial autocorrelation analysis, there is no obvious spatial similarity distribution of grain crops in Sichuan, and the economic crops have obvious accumulation characteristics of high-high cluster and low-low cluster. Global Moran's I index of cotton and sugar has obvious phased characteristics, and the spatial autocorrelation of Oil-bearing crops is decreased.

(3) Based on the local spatial autocorrelation analysis, the planting industry in some parts of Sichuan Province has significant spatial disequilibrium distribution characteristics, there are significant high-high cluster, low-low cluster and high-low cluster. It shows that in some areas, the interregional spatial correlation and heterogeneity of planting industry in Sichuan is obvious, and has strong spatial spillover effect.

According to the above research conclusions, this paper believes that the optimization of regional resources allocation, the promotion of agricultural modernization and the transformation of agricultural economic development mode, must further optimize the spatial layout of the planting industry. One is to guide the optimal allocation of production elements in space and industry through policy inclination, and promote the construction of national agricultural demonstration areas and the construction of the "National Agricultural Economic Zone" across the region. Second, based on the comparative advantages of regional agriculture and resource endowment, according to the orientation of urban development and the main function of agriculture, the spatial distribution and industrial development goal of the superior regions of crops are further clarified. Third, in the context of the weakening of the role of natural agglomeration, we should give full play to the role of social agglomeration, effectively utilize the opportunities of technological innovation and institutional innovation, improve the exchange and cooperation of technology and information among regions, and enhance the spatial linkage and radiation ability of high-high agglomeration region.

\section{Acknowledgments}

This paper was supported by the Soft Science Research Program of Sichuan Province (Grant No.2017ZR0163),the 13th Five-Year Plan of Social Sciences in Sichuan Province for the year 2016(Grant No.SC16B020) and the Key Laboratory of Statistical Information Technology and Data Mining, Stae Statistics Bureau(Grant No.SDL201709).

\section{References}

[1] Xiao Weidong. Geographical agglomeration of planting Industry in China: temporal and Spatial characteristics, changing trend and influencing factors $[\mathrm{J}]$. Chinaundefineds rural economy is 28 : 19-31.

[2] Aciksoz S. The cluster of urban agriculture:Case of Bartin-Turkey[J]. Journal of Agricultural Sciences, 2009, 15(4): 348-357.

[3] Mutlu M N. Organic Agriculture Cluster in Southeast Anatolia Region of Turkey: A collaborative initiative to foster local economic development [J]. 2014.

[4] Chatterjee T, Ganeshkumar A. Geographic Neighbourhood and Cluster Formation: Evidence from Indian Agriculture [J]. Journal of Development Studies, 2016, 52(11):1-16.

[5] Porter M E. The Competitive Advantage of Nations, London: Macmillan, 1990. 
[6] Li Erling, Pang Anchao, Zhu Jiguang. Evolution and mechanism of AGG pattern in China. Geographical research, 2012(5): 887-898.

[7] Wang Yanrong, Liu Yizheng. The structure verification of agglomeration formation mechanism of agriculture industry. Chinaundefineds Rural economy, 2011(10): 77-85.

[8] Deng Zongbing, Feng Yonggang, Zhang Junliang, Wang Ju, Tian Weibo. Spatial and temporal characteristics, Evolution trend and effect Analysis of Geographical agglomeration in China [J]. Chinaundefineds Agricultural Sciences, 2013(22): 4816-4828. 